\title{
Факторы демографического развития Луганского региона: общественно-географический аспект
}

\author{
Н.С. Краснокутская凶 \\ Луганский начиональный университет им. Тараса Шевченко, Украина \\ (91000, г. Луганск, ул. Оборонная, 2) \\ Поступила в редакциию 6.11.2019 \\ Принята к публикаиии 26.02.2020
}

\begin{abstract}
Аннотация: Устойчивость социально-экономического развития и обеспечение национальной безопасности каждой страны во многом предопределяется особенностями демографического развития. Благоприятная демографическая ситуация региона является важным условием и не менее важным результатом ее эффективного социально-экономического развития. Недостаточный учет трансформации демографических процессов, является одним из факторов наращивания препятствий к сбалансированному развитию. Особенную практическую значимость исследования такой направленности имеют в регионах со сложной социально-экономической и внутриполитической ситуацией, к которым принадлежит Луганский регион. Луганщина - регион старопромышленного типа с крайне неблагополучной демографической ситуацией, характеризующийся сильной контрастностью и высокой социально-экономической поляризацией территории. Регион характеризуется депопуляционными процессами, которые имеют чрезвычайно интенсивный характер.

Цель статьи - изучение региональных факторов трансформации демографического развития Луганщины для периода 1985-2018 годов. В статье раскрыты особенности влияния социально-экономических, демографических, брачно-семейных, медико-социальных и экологических факторов на динамические изменения основных процессов воспроизводства населения. Обозначена специфика трансформации воспроизводства населения в Луганском регионе под действием отдельных групп факторов. Основные результаты исследования подтверждаются официальными статистическими данными. Определены приоритетные направления формирования демографической политики в Луганщине.
\end{abstract}

Ключевые слова: демографическое развитие, демографические процессы, динамика, население, структура, трансформации, факторы, регион.

\section{Factors of Demographic Development of the Lugansk Region: Social and Geographic Aspect}

\section{N.S. Krasnokutskaya ${ }^{\bowtie}$}

Abstract: Sustainability of socio-economic development and ensuring national security of each country is largely determined by the characteristics of demographic development. A favourable demographic situation in the region is an important condition and no less important result of its effective socio-economic development. Lack of accounting for the transformation of demographic processes is one of the factors that build up obstacles to balanced development. Studies of this orientation are of particular practical importance in regions with a difficult socio-economic and domestic political situation, to which the Lugansk region belongs. Lugansk region is a region of the old industrial type with an extremely unfavourable demographic situation, characterized by strong contrast and high socio-economic polarization of the territory. The region is characterized by depopulation processes that are extremely intense.

(C) Краснокутская Н.С., 2020

凶 E-mail: nadya gaev@mail.ru

(c) (i) Контент доступен под лицензией Creative Commons Attribution 4.0 License.

The content is available under Creative Commons Attribution 4.0 License. 
In this regard, the aim of the work was to study the regional factors of transformation of the demographic development of the Luhansk region. The study was conducted for the period 1985-2018. The article reveals the features of the influence of socio-economic, demographic, marriage, family, medical, social and environmental factors on the dynamic changes in the basic processes of population reproduction. The specificity of the transformation of population reproduction in the Lugansk region under the influence of certain groups of factors is indicated. The main results of the study are confirmed by official statistics. The priority areas for the formation of a demographic policy in the Luhansk region are identified.

Key words: demographic development, demographic processes, dynamics, population, structure, transformations, factors, region.

\section{ВВЕДЕНИЕ}

Население - главная составляющая общественно-географического комплекса. Стратегическое планирование комплексного развития территории включает анализ и прогнозирование изменений демографической ситуации. Значимость демографических процессов и их проблемный характер определяют повышенное внимание к ним со стороны представителей не только демографии, но и экономики, социологии, культурологи, этнографии, а также общественной географии, а именно: географии населения (геодемографии).

Главной задачей геодемографии является раскрытие системы связей воспроизводства народонаселения с общественным развитием на региональном уровне. География населения обладает мощным теоретико-методологическим и методическим потенциалом исследования демографических процессов.

Несмотря на широкое представление среди общественно-географических трудов проблематики демографического развития, остаются недостаточно изученными региональные исследования. Преимуществом региональных социально-демографических исследований является то, что они позволяют определить адресные меры демографической политики с учетом специфики сложившейся ситуации в конкретном регионе.

Повышенную актуальность в проведении такого рода исследований имеют регионы, в которых демографические процессы имеют продолжительный отрицательный тренд изменений. К категории таких регионов принадлежит Луганский регион.

В контексте выше изложенного, целью нашей статьи является анализ региональных факторов трансформации демографического развития Луганщины.

\section{МАТЕРИАЛЫ И МЕТОДЫ ИССЛЕДОВАНИЯ}

Информационную базу исследования составили официальные статистические данные Государственного комитета статистики. Исследованием охвачен период 1985-2018 годов.

\section{ОБСУЖДЕНИЕ РЕЗУЛЬТАТОВ}

Особенности воспроизводства населения Луганского региона, начиная с 1990-х годов, можно охарактеризовать как остропроблемные. Это отображается через отрицательный естественный прирост в результате высоких показателей смерт-

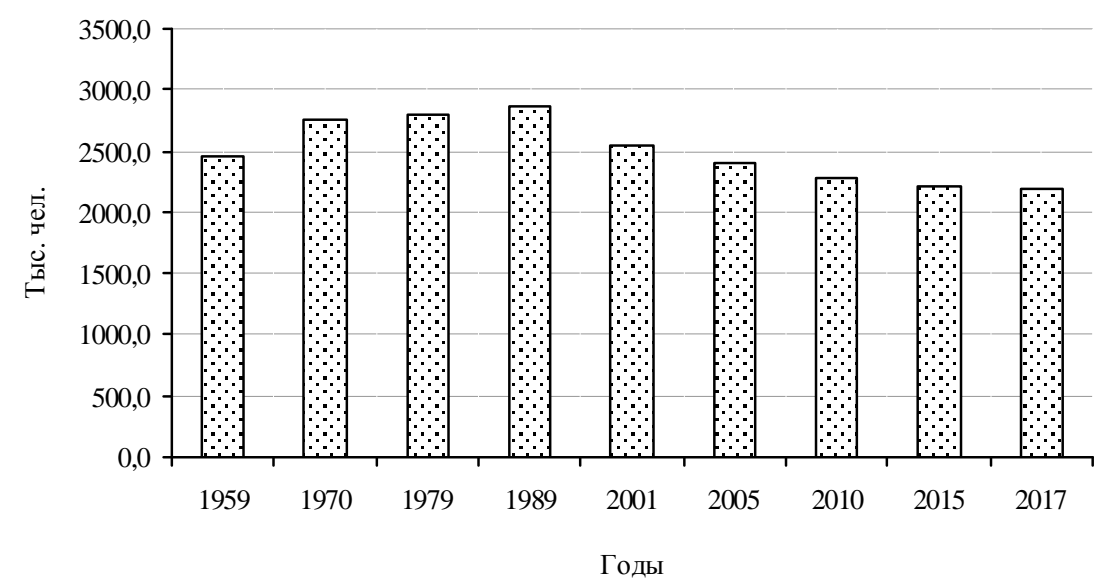

Puc. 1. Динамика численности населения Луганщины в 1959-2017 годы (составлено автором по данным Госкомстата Украины)

[Fig. 1. The dynamics of the population of the Luhansk region in 1959-2017 (compiled by the author according to the State Statistics Committee of Ukraine)] 


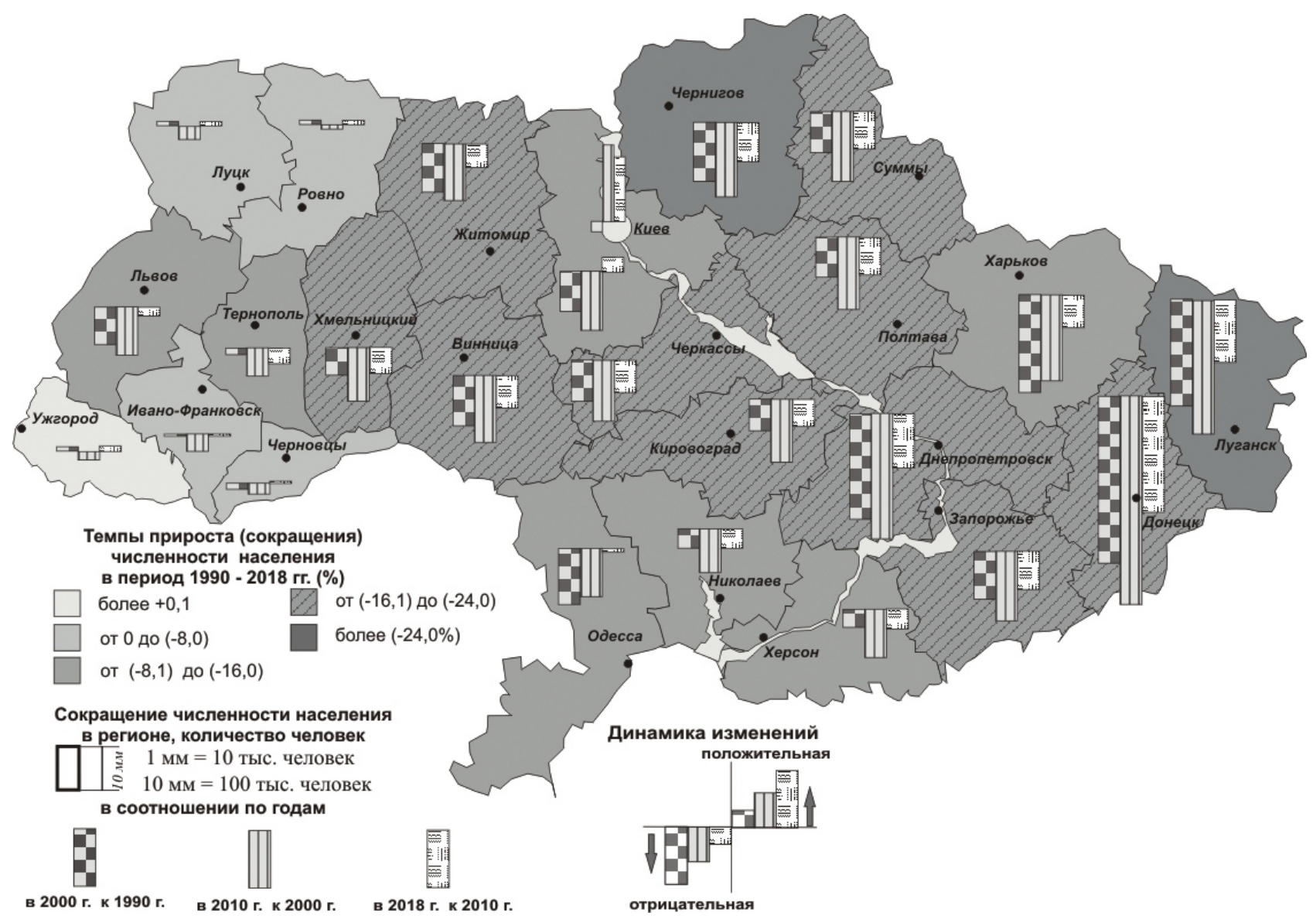

Puc. 2. Темпы сокращения (прироста) численности населения в регионах Украины в период с 1990-2018 годы (составлено автором по данным Госкомстата Украины)

[Fig. 2. The rate of decline (growth) in population in the regions of Ukraine from 1990-2018 (compiled by the author according to the State Statistics Committee of Ukraine)]

ности и низких - рождаемости; малую долю населения моложе трудоспособного возраста и большую - лиц старших возрастов; значительный механический отток населения. Процессы рождаемости и смертности, характерные для всего прошлого столетия Луганщины, сильно деформировали возрастную структуру населения региона, привели к «провалам», которые влияют на динамику численности населения сегодня и будут воздействовать в течение текущего столетия (рис. 1).

Нисходящий тренд изменений численности населения (рис. 2) является свидетельством нарастающей угрозы нехватки трудовых ресурсов, роста социального напряжения за счет увеличения экономической нагрузки пожилыми людьми на трудоспособное население, что в итоге может привести к постепенному вымиранию региона Луганщины и как следствие нарушит возможности ее комплексного развития.

Общие тенденции демографического развития Луганского региона, как закономерные процессы характерные для регионов стран Европы в целом, в основном согласуются с концепцией демографического перехода. Он описывает и объясняет переход от модели общества, которое имеет треугольную молодую возрастную структуру - с высокой рождаемостью и высокой смертностью, к гипотетической постпереходной модели общества с прямоугольной возрастной структурой, где существует низкая рождаемость и низкая смертность [3]. Однако, опыт европейских стран показывает, что сам демографический переход будет болезненным и затяжным без реализации мер государственного урегулирования демографических процессов.

Изменениям демографического процесса предшествует совокупность факторов (рис. 3). Факторы - это цепь причинно-следственных связей, условия, регулирующие количественные и качественные характеристики процесса, которые составляют в совокупности механизм процесса. Выявление особенностей действия тех или иных факторов в пределах конкретного региона позволяет 
установить приоритетные направления региональной демографической политики. Анализ различных показателей демографического развития позволил выявить следующие факторы трансформации демографических процессов на Луганщине.

Соииально-экономические факторы. Все естественные демографические события происходят не просто с людьми, а с людьми, проживающими в конкретной общественной среде, которые определяют общие стандарты уровня и качества жизни. Превалирование в обществе стандартов о полной экономической и финансовой самостоятельности, как о главном условии для создания благополучной семьи и рождения детей, предопределяет высокую значимость социально-экономических факторов в контексте демографического развития региона.

В экономически развитых обществах низкий уровень жизни тесно коррелирует с низкими значениями рождаемости. Многочисленными исследованиями доказано, что в периоды экономических кризисов деторождения, как правило, откладываются, а уровень рождаемости населения достигает критически низкой отметки.

Социально-экономические факторы, начиная с 1990-х годов, являются причиной низкой репродуктивной активности населения Луганщины, когда началась первая волна обвала экономики в условиях рыночных преобразований. Именно в этот период, как и во всей Украине, около 90,0\% населения региона попало за черту бедности. С течением времени проблема низкого уровня жизни населения Луганщины не исчезла. Несмотря на то, что индустриально развитый Луганский регион на протяжении 1990-2013 годов входил в пятерку регионов с наибольшим размером оплаты труда, но уровень бедности его населения оставался стабильно высоким. Согласно результатам мониторинга, в течение 2002-2008 годов Луганский регион входил в первую десятку «самых бедных» регионов Украины, и только в 2009-2012 годах его позиции в рейтинге несколько улучшились (рис. 4).

Однако, нарушение внутриполитической ситуации после 2014 года, спровоцировали новую волну экономического кризиса в регионе. Всякие экономические трансформации сопровождаются негативными явлениями, такими как: спад производства, рост уровня безработицы, задолженность по выплате заработной платы, снижение размеров оплаты труда и прочее - все это соответствует современному социально-экономическому развитию Луганщины. Одним из подтверждений этого яв-

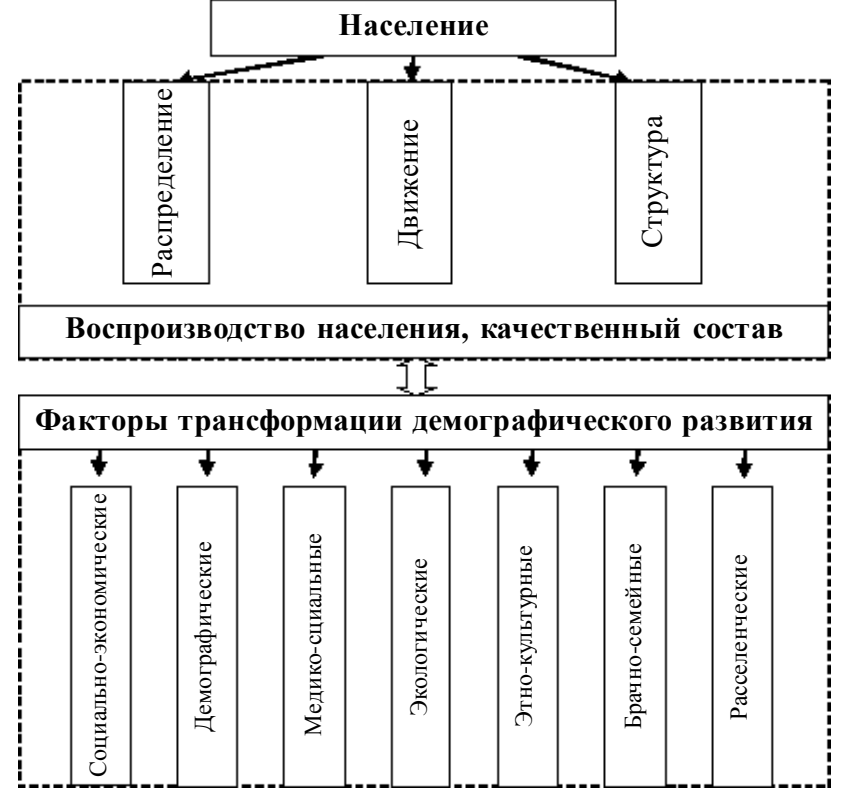

Puc. 3. Факторы формирования и трансформации геодемографических процессов в регионе (по А.Г. Топчиеву [6])

[Fig. 3. Factors of formation and transformation of geodemographic processes in the region (according to A. Topchiev [6])]

ляется спад объемов в социально-экономической сфере: объемы реализованной промышленной продукции - на 80,9\%; объемы розничного товарооборота - на 98,2\%; объемы реализованных услуг - на 81,7\% (сравнение приведено между 2013 и 2015 гг.).

Современные социально-экономические преобразования Луганщины реализуются в условиях внутриполитической нестабильности, что привносит дополнительные испытания для жизни населения. Согласно экспертным оценкам уровня жизнедеятельности домохозяйств уровень бедности населения Луганщины в 2016 году составил 42,5\%, что было вторым из самых высоких показателей среди регионов Украины. На текущий момент социально-экономические факторы оказывают наибольшее влияние в изменении демографических процессов в Луганском регионе.

Демографические факторы проявляются, в первую очередь, через особенности половозрастной структуры населения. Изменения в общей численности населения провоцируют изменения в разных возрастных группах мужского и женского населения. В условиях затяжной депопуляции, происходят значительные деформации половозрастной структуры населения (рис. 5), при этом системно сокращается репродуктивный контингент. 


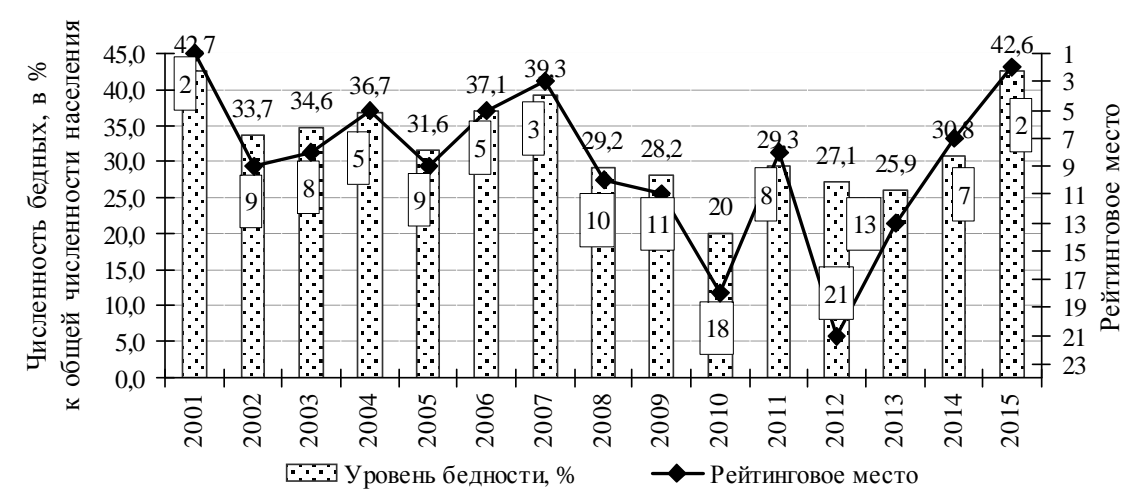

Puc. 4. Уровень бедности населения и рейтинговая позиция Луганщины среди регионов Украины

[Fig. 4. The poverty level of the population and the rating position of the Luhansk region among the regions of Ukraine]

В нашем исследовании рассмотрим динамику численности женщин в возрасте наиболее значительного вклада в рождаемость - 18-44 лет.

Анализ данных половозрастных пирамид населения Луганщины показал, что на протяжении 1989-2018 годов численность этой возрастной группы женщин системно сокращается.

Так, если в 1989 году численность женского населения в возрасте 18-44 лет составляла 1050,3 тыс. чел., то в 2000 году число женщин этой категории сократилось на 42,0 тыс. чел. (96,0 \% от 1989 г.); а в 2010 году - на 144,9 тыс. чел. (86,2\% от 1989 г.); в 2018 году - на 259,8 тыс. чел. (75,3\% от 1989 г.). Соответственно, с одной стороны, численность родившихся детей в регионе зависит от количества и сбалансированности населения, а с другой - уменьшение когорты населения репродуктивного возраста обусловлено низкими значениями рождаемости населения, как результат проявления «демографических волн».

Общий нисходящий тренд изменений численности населения репродуктивного возраста на фоне всеобщей депопуляции, свидетельствует о том, что доля населения репродуктивного возраста в Луганском регионе будет и в дальнейшем сокращаться. Это является серьезным вызовом для демографической политики региона.

Наряду с общим сокращением в регионе количества женщин, способных выполнять детородную функцию, меняется интенсивность рождений. Так, суммарный коэффициент рождаемости в целом для региона с 1990 до 2013 года сократил свое значение - с 1,7 до 1,3. При этом в кризисный период экономического развития в начале 1990-х годов этот показатель достигал размерность в 0,9 детей (для элементарного замещения поколений необходим суммарный коэффициент рождаемости - 2,3).
На протяжении анализируемого периода изменились коэффициенты рождаемости по возрасту матери. В целом следует отметить, что с 1990 по 2013 год число живорожденных детей на 1000 женщин-метерей детородного возраста сократилось на 11,2. При этом за 1995-2013 годы коэффициенты рождаемости в возрастных группах младше 20 лет и 20-24 лет уменьшились, а в старших возрастных группах - увеличились. В частности: среди матерей в возрасте 25-29 лет в 1,5 раза; в возрасте 3034 лет - в 2,3 раза; в возрасте 35-39 лет - в 2,8 раза; в возрасте 40-44 лет - в 2,1 раза (таблица).

Соответственно, можно отметить, что средний возраст матери также увеличился, а значит реализация деторождений, как правило, откладывается на более зрелый период жизни, что влияет на отсрочивание вероятности рождения вторых и последующих детей. В этом контексте более поздний возраст матери при рождений детей определяет тенденцию снижения общего уровня рождаемости в регионе.

Брачно-семейные факторы. Существенно не только наличие достаточной совокупности лиц детородного возраста, а их сбалансированность по полу, которая создает основу конъюнктуры «брачно-семейного рынка». В условиях социально-экономического и демографического кризиса нередко нарушаются половые пропорции, и возникает нехватка мужского населения. Согласно данным половозрастных пирамид, на Луганщине на протяжении 1989-2018 годов наблюдается сохранение гендерной асимметрии.

Важно отметить, что в Луганском регионе диспропорция полов в пользу преобладания удельного веса женщин начинается с возрастной группы 35-39 лет. Эта тенденция обусловлена высоким уровнем естественной смертности муж- 


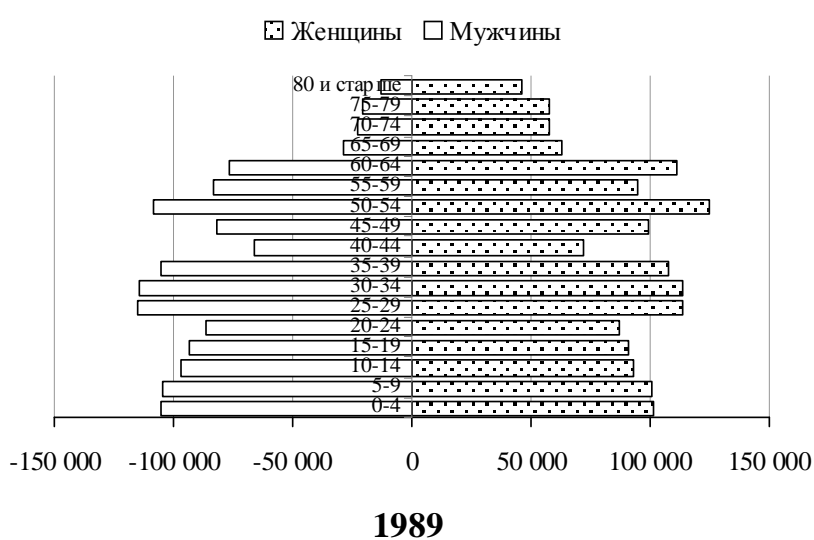

1989

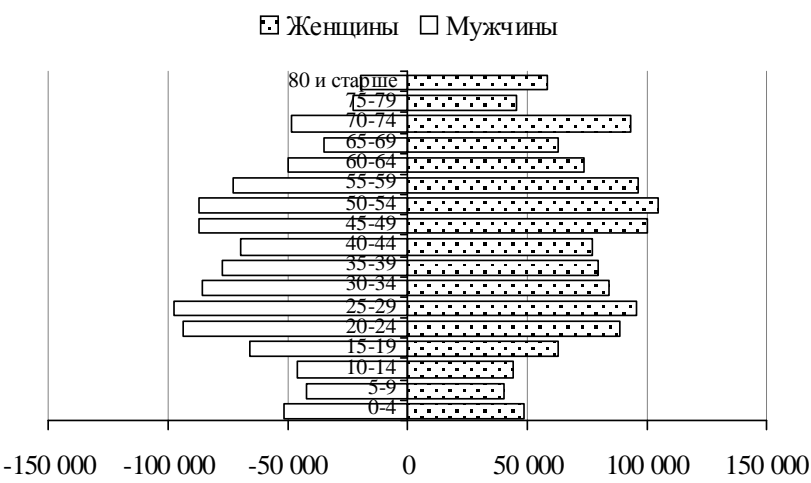

2010
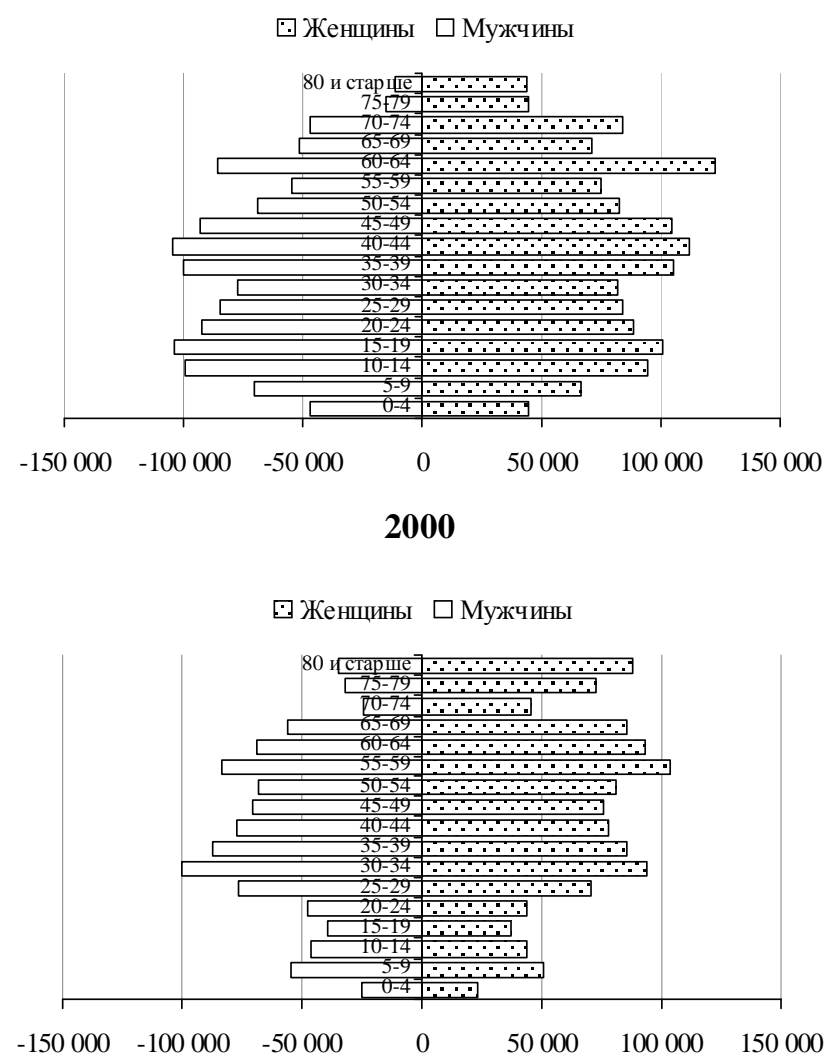

2018

Puc. 5. Половозрастные пирамиды населения Луганщины (составлено автором по данным Госкомстата Украины [2])

[Fig. 5. Age and gender pyramids of the Luhansk region population (compiled by the author according to the State Statistics Committee of Ukraine [2])]

чин в молодом возрасте и улучшенными показателями продолжительности жизни женщин. Анализ данных соотношения численности мужчин и женщин показал, что в Луганском регионе лучше «обеспечены» мужчинами-партнерами женщины молодой возрастной группы 16-29 лет, а именно на каждую тысячу этих женщин приходится в среднем 1470 мужчин в возрасте 2034 лет. Тогда, как на 1000 женщин старшего репродуктивного возраста (30-44 лет) приходится около 905 мужчин в возрасте 35-49 лет. В целом соотношение мужчин и женщин по основным группам репродуктивного возраста, позволяет констатировать достаточно благоприятную ситуацию для формирования брачно-семейных отношений в регионе.

Однако уровень рождаемости в регионе зависит от собственно брачной и детородной активности населения, которые, как правило, тесно взаимообусловлены между собой. Современное общество ориентируется на свободу в семейных отношениях, но еще столетие назад существовали же- сткие рамки брачного и репродуктивного поведения. На современном этапе развития семейных отношений существует форма организации семьи женщины и мужчины - «фактический брак». Государственными нормами это, конечно, не запрещается, но традиционные понимание брачно-семейных отношений все больше теряют свою ценность в общественном понимании. Главными факторами колебаний показателей брачной структуры является, прежде всего, социальные и экономические катаклизмы [7].

Анализ динамики коэффициентов брачности населения в Луганском регионе с 1989 по 2015 год, свидетельствует о снижении их значений. В течение этого периода количество зарегистрированных браков в расчете на 1000 жителей здесь сократилось почти в 4,5 раза. При этом важно отметить, что за анализируемый период уровень разводимости в регионе также снизился - в 10,5 раз, составив, согласно официальным данным статистики, в 2015 году всего 0,4\%о. Положительный тренд изменений в количестве разводов является зако- 
Коэффициент рождаемости по возрастным группам матери среди населения Луганщины (составлено автором по данным Госкосмстата Украины [2]) (на 1000 женщин соответствующей возрастной групnь) [Table. Birth rate by age group of mother among the population of the Luhansk region (compiled by the author according to the State Statistics Committee of Ukraine [2]) (per 1000 women of the corresponding age group)]

\begin{tabular}{|l|c|c|c|c|c|c|c|}
\hline \multirow{2}{*}{$\begin{array}{c}\text { Возрастные группы, лет } \\
\text { [Age groups, years] }\end{array}$} & \multicolumn{7}{|c|}{ Годы [Years] } \\
\cline { 2 - 8 } $\begin{array}{c}\text { Женщины в возрасте 15 - 49 лет } \\
\text { [women ages 15 - 49] }\end{array}$ & 1995 & 2000 & 2005 & 2010 & 2011 & 2012 & 2013 \\
\hline в том числе / including & & 23,8 & 27,8 & 36,2 & 37,7 & 39,4 & 38,1 \\
\hline младшем за 20 лет [younger for 20 years] & 56,4 & 29,6 & 26,5 & 29,7 & 28,9 & 28,2 & 27,3 \\
\hline $20-24$ & 103,0 & 81,1 & 75,6 & 80,9 & 81,3 & 83,4 & 81,7 \\
\hline $25-29$ & 50,6 & 42,5 & 55,5 & 71,0 & 74,0 & 78,4 & 75,1 \\
\hline $30-34$ & 21,1 & 19,4 & 29,9 & 44,7 & 47,9 & 52,1 & 49,5 \\
\hline $35-39$ & 7,5 & 5,4 & 9,6 & 17,6 & 20,3 & 20,8 & 21,4 \\
\hline $40-44$ & 1,3 & 1,0 & 1,6 & 2,8 & 3,6 & 3,3 & 3,8 \\
\hline $45-49$ & 0,1 & 0,0 & 0,0 & 0,1 & 0,1 & 0,1 & 0,1 \\
\hline $\begin{array}{l}\text { Суммарный коэффициент рождаемости } \\
\text { [Tотаl fertility rate] }\end{array}$ & 1,2 & 0,9 & 1,0 & 1,2 & 1,3 & 1,3 & 1,3 \\
\hline
\end{tabular}

*Количество детей, которое может родить в среднем одна женщина при существующем уровне плодовитости. [* The number of children that an average woman can give birth to at the current level of fertility.]

номерным следствием сокращения количества зарегистрированных браков.

Популярность на так называемые «консенсуальные» браки приобретает всеобщее распространение, и, как правило, состояние в условиях семейной неопределенности обретает хронические формы. Последнее еще больше ограничивает вероятность выполнения детородной функции молодых поколений.

Немаловажно в этом контексте отметить полярность моделей репродуктивного поведения мужчин и женщин. Объективным условием самореализации личности, несмотря на стремление к экономической независимости, остается выполнение ею социальной роли «родитель», которая для женщины, несмотря на современные технологии репродуктивной медицины, имеет возрастные ограничения. Осознание этого провоцирует из года в год все большее количество женщин на рождение ребенка без официального семейного статуса. В результате за последние двадцать лет (19952015 гг.) доля внебрачных рождений в Луганском регионе возросла вдвое. Если в 1995 году в регионе доля детей, рожденных женщинами, которые не находились в зарегистрированном браке, составляла $15,2 \%$ к общей численности рожденных, то в 2015 году удельный вес таких детей был равным $30,6 \%$.
При этом распространение внебрачной рождаемости носит более прогрессивный характер для сельской местности, где с 1995 по 2015 год доля внебрачных детей выросла в 2,8 раза (с 13,3\% до $36,9 \%$ ), тогда как в городской местности это увеличение составило 1,8 раза (с 15,5\% до 28,4\%). Одновременно с этим в регионе увеличилось количество нуклеарных семей с детьми, возглавляемых женщинами.

Важно отметить, что проблема нуклеаризации семей выходит далеко за рамки причины низкой рождаемости, она влияет и на качественные характеристики рожденных поколений, которые с течением времени будут формировать общий человеческий потенциал региона. В частности, специальными социологическими исследованиями российских ученых доказано, что дети в неполных семьях рождаются менее здоровыми из-за нестабильных отношений с партнером по сравнению с теми, кто рожден женщинами, состоящими в браке. Соответственно, популяризация в обществе мнения о гармоничности брачно-семейных отношений весьма важная задача формирования положительных норм репродуктивного поведения в регионе.

Медико-сочиальные факторы. Эта группа факторов носит как прямое, так и опосредованное влияние на особенности изменения демографической ситуации. Первоочередное значение, можно оп- 


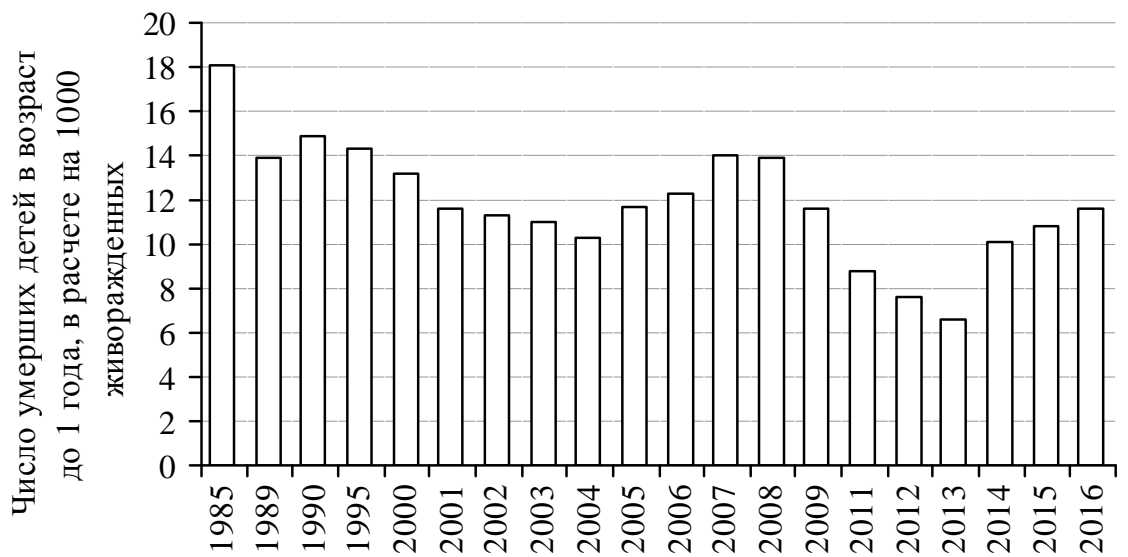

Годы

Puc. 6. Динамика коэффициента младенческой смертности в Луганщине (составлено автором по данным Госкомстата [5])

[Fig. 6. Dynamics of infant mortality rate in the Luhansk region (compiled by the author according to the State Statistics Committee [5])]

ределить степенью доступности и уровнем качества медицинских услуг предоставляемых населению. Один из главных индикаторов - высокий уровень младенческой смертности, который, несмотря на общий положительный тренд снижения, сохраняет высокие значения (рис. 6). При этом Луганщина на протяжении 2000-2016 годов по уровню смертности младенцев входит в пятерку «лидеров» среди регионов Украины.

Ретроспективный анализ позволил нам установить, что на протяжении 1990-2016 годов в регионе сократилось количество медицинских учреждений и при этом существенно ухудшилось качество и доступность к услугам системы здравоохранения. Общее количество больничных учреждений в Луганском регионе снижается. Вопервых, за счет закрытия подобного типа учреждений на юге региона, находящихся на содержании промышленных предприятий, ставших банкротами; а во-вторых, - за счет «вымирающих» сельских поселений северной части региона. Такая ситуация неизбежно приводит к росту уровня смертности из-за неспособности населения получить надлежащую и своевременную медицинскую помощь.

Согласно выборочным обследованиям домохозяйств по состоянию здоровья в 2012 году, установлено, что более трети $(35,0 \%)$ домохозяйств Луганщины, члены которых нуждались, но не получили медицинской помощи, сообщили о случаях невозможности посетить врача. В 46,0\% случаях, опрашиваемые объяснили это высокой стоимостью услуг; 44,0 \% - слишком длинной очере- дью; каждый десятый - отсутствием медицинского специалиста нужного профиля [5].

В условиях внутрирегионального кризиса в регионе уровень медицинского обслуживания ухудшился. В 2014 году среднее количество койко-мест по региону составило 22,1 единиц в расчете на 10000 населения, а количество посещений за смену 78,4. В сравнении со средними показателями по Украине это было меньше в 3,5 раза и в 2,7 раза, соответственно.

Косвенное влияние этой группы причин усматривается в формировании значительной гендерной асимметрии населения. Отметим, что Луганщина относится к регионам с очень высоким уровнем смертности мужчин. В 2013 году общий коэффициент смертности для них составлял 17,2\%о против $14,9 \%$ у женщин. Как видно из структурной диаграммы (рис. 7), смертность мужчин превышает смертность женщин уже после 20-летнего возраста, но в интервале от 40 до 64 лет это превышение особенно велико (многократное). Разница в средней продолжительности жизни между мужчинами и женщинами на протяжении 1990-2015 годов сохраняется и составляет не менее 10 лет.

Глубинные причины названных процессов формирования диспропорции полов связаны преимущественно с падением здоровья населения, в частности мужчин трудоспособного (репродуктивного) возраста. Учет состояния здоровья населения осложнен отсутствием соответствующих статистических данных. Однако, анализ нозологий причин смертности свидетельствует о том, что наряду с эндогенными причинами (сердечно-со- 


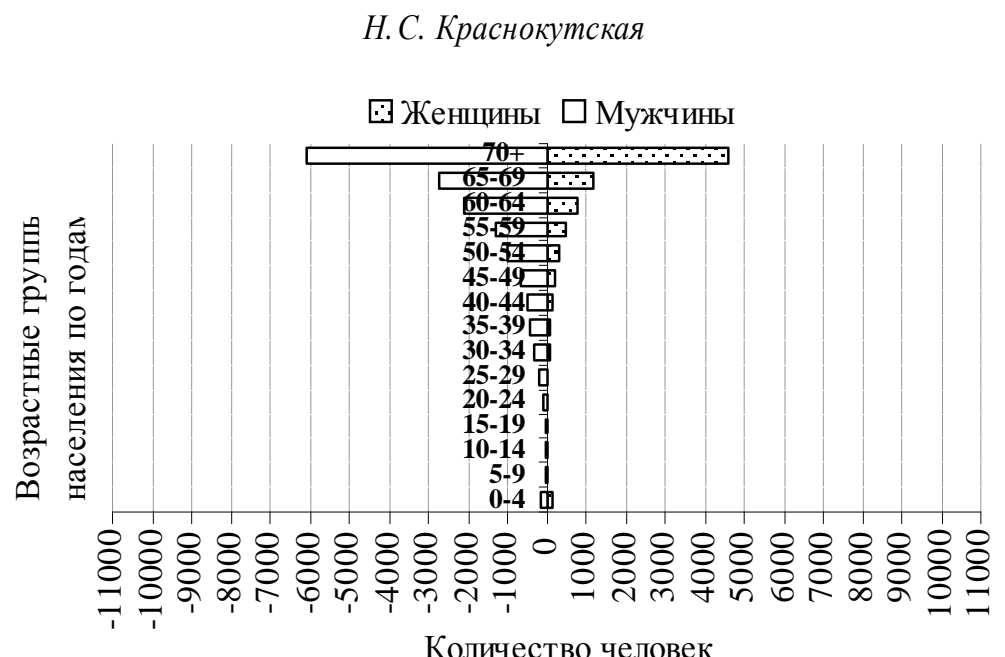

Puc. 7. Половозрастная структура умершего в 2015 г. населения Луганщины (составлено автором по данным Госкомстата Украины [2])

[Fig. 7. Sex and age structure of the deceased in 2015 the population of Lugansk region (compiled by the author according to the State Statistics Committee of Ukraine [2])]

судистые заболевания, болезни дыхательных путей, онкология), высокой является смертность по экзогенным причинам (алкоголизм, наркомания, самоубийство).

Распространение среди населения болезней экзогенного характера связано со спецификой трудовой деятельности населения. Так, для Луганщины, как индустриального региона, специализация которого связана с отраслями тяжелой промышленности, основным местом работы мужского населения является производственная сфера на старопромышленных предприятиях. Они, в свою очередь, отличаются повышенным уровнем травматизма и низким уровнем санитарно-гигиенических условий труда. К тому же население, занятое в таких тяжелых условиях, как правило, непритязательно относится к своему здоровью, поэтому чаще подвержено к вредным привычкам.

Анализ статистических данных подтверждает, что среди регионов Украины, именно для Луганщины на протяжении 2001-2013 годов было характерным 1-3 место по наибольшей доле работающего населения, которое отсутствовало на работе по причине болезни. Зная риски заболеваний различными нозологиями и проблему качественной медицины, можно целенаправленно воздействовать на механизмы, регулирующие процессы демографии.

Экологические факторы. Вследствие сосредоточения в регионе экологически вредных производств угледобывающей, металлургической, химической, теплоэнергетической отраслей, а также в условиях высокой плотности населения, здесь сформировалось крайне неудовлетворительное состояние окружающей среды. Экологическое неблагополучие региона, несомненно, поступательно влияет на здоровье и продолжительность жизни всех групп населения. Учеными доказано, что состояние здоровья населения прямым образом зависит от экологического состояния окружающей среды. По состоянию на 2013 год в рейтинге регионов Украины по такому индикатору индекса человеческого развития, как «Окружающая природная среда» среди 25 регионов Украины, Луганский занял 22 место, войдя в последнюю тройку общего рейтинга. Луганщина стабильно входит в группу тех регионов, которые отличаются значительными объемами экологически опасных промышленных выбросов в окружающую среду. Так, по официальным данным в течение 2005-2013 годов среди населения Украины наибольшее количество выбросов вредных веществ в атмосферный воздух от стационарных и передвижных источников приходилось на одного жителя Донецкого, Днепропетровского и Луганского регионов. Такая экологическая опасность негативным образом влияет на состояние здоровья жителей Луганщины [1].

\section{ЗАКЛЮЧЕНИЕ}

Демографические изменения, если их не учитывают как основную составляющую социальноэкономической политики и стратегии развития региона, всегда приходятся «не ко времени». Демографические изменения требуют адаптации всех экономических и социальных институтов к новым условиям [4]. Однако, именно демографический потенциал на современном этапе общественноисторической формации, определяет резервы формирования социально-экономического благополу- 
чия Луганщины. Сложившееся социально-экономическое и демографическое положение в регионе, требует определения приоритетных направлений решения вопросов демографического развития региона, связанных с проблемами социального, экономического, демографического, инфраструктурного, экологического развития и стабилизации внутриполитической ситуации.

\section{СПИСОК ЛИТЕРАТУРЫ}

1. Гаєвська Н.С. Соціальні фактори поширення бідності населення (на прикладі Луганської області) // Економічна та соціальна географія, 2011, №2 (63), c. $92-100$.

2. Госкомстат Украины: Банк данных. Доступно: http://database.ukrcensus.gov.ua/MULT/Dialog/ statfile_c.asp. (дата обращения: 22.08.2019).

3. Зеликова Ю. А. Стареющая Европа: демография, политика, социология. СПб., Норма, 2014. 224 с.

4. Римашевская Н.М., Доброхлеб В.Г., Кислицына О.А. Демографические перемены в России как предпосылка модернизации системы образования // Народонаселение, 2009, № 1, с. 4-17.

5. Самооцінка населенням Луганської області стану здоров'я та рівня доступності окремих видів медичної допомоги у 2012 році : Статистичний збірник / Головне управління статистики у Луганської області: УПравління обстежень домогосподарств. Луганськ, 2013. Доступно: http://www.lg.ukrstat.gov.ua. (дата обращения: 30.05.2019).

6. Топчієв О.Г., Яворська В.В. Стадії формування геодемографії // Наукові пошуки географічной громадськості: минуле, сьогодення, майбуття: матеріали Всеукр. наук.-практ. конф., присвяченої 75-річчю утворення Луганської області. Луганськ, 2013, с. 56-62.

7. Чеботарева Н.М., Бахмут Ю.О. Современная брачная структура населения Луганской области // Економічний вісник Донбасу, 2016, № 2 (44), с. 4-8. Доступно: http://dspace.nbuv.gov.ua/bitstream/handle/ 123456789/107716/0-TitlePages.pdf. (дата обращения: 22.05.2019)

\section{КОНФЛИКТ ИНТЕРЕСОВ}

Автор декларирует отсутствие явных и потенциальных конфликтов интересов, связанных с публикацией настоящей статьи.

Краснокутская Надежда Сергеевна кандидат географических наук Луганского национального университета им. Тараса Шевченко, г. Луганск, Украина, ORCID: https://orcid.org/0000-0002-6246-325x, E-mail: nadya_gaev@mail.ru

\section{REFERENCES}

1. Ga€vs'ka N.S. Social'ni faktori poshirennja bidnosti naselennja (na prikladi Lugans'koï oblasti) [Social factors of poverty spread (for example, Luhansk region)]. Ekonomichna ta social'na geografija, 2011, no. 2 (63), pp. 92-100. (In Ua.)

2. Goskomstat of Ukraine: Databank. (In Ua.) Available at: http://database.ukrcensus.gov.ua/MULT/Dialog/ statfile_c.asp. (accessed 22.08.2019).

3. Zelikova Ju. A. Starejushhaja Evropa : demografija, politika, sociologija [Aging Europe: Demography, Politics, Sociology]. St. Petersburg., Norma, 2014. 224 p. (In Russ.)

4. Rimashevskaja N.M., Dobrohleb V.G., Kislicyna O. A. Demograficheskie peremeny v Rossii kak predposylka modernizacii sistemy obrazovanija [Demographic changes in Russia as a prerequisite for the modernization of the education system]. Narodonaselenie, 2009, no. 1, pp. 4-17. (In Russ.)

5. Self-assessment by the population of Luhansk Oblast of the state of health and the level of availability of certain types of medical care in 2012: Statistical collection. Golovne upravlinnja statistiki u Lugans'koï oblasti: Upravlinnja obstezhen' domogospodarstv. Lugans'k, 2013. (In Ua.) Available at: http://www.lg.ukrstat.gov.ua. (accessed 30.05.2019)

6. Topchiєv O. G., Javors'ka V. V. [Stages of formation of geodemography] Naukovi poshuki geografichnoj gromads'kosti: minule, s'ogodennja, majbuttja: materiali Vseukr. nauk.-prakt. konf., prisvjachenoï 75-richchju utvorennja Lugans'koï oblasti [Scientific research of the geographical public: past, present, future: materials. AllUkrainian. Research Practice conf.]. Lugans'k, 2013, pp. 5662. (In Ua.)

7. Chebotarjova N.M., Bahmut Ju. O. Sovremennaja brachnaja struktura naselenija Luganskoj oblasti [The modern marriage structure of the population of Lugansk region]. Ekonomichnij visnik Donbasu, 2016, no. 2 (44). (In Russ.) Available at:http://dspace.nbuv.gov.ua/bitstream/ handle/123456789/107716/0-TitlePages.pdf. (accessed 22.05.2019).

\section{CONFLICT OF INTEREST}

The author declares no information of obvious and potential conflicts of interest related to the publication of this article.

Nadezhda S. Krasnokutskaya

Cand. Sci. (Geogr), Assoc. Prof. at the Department of Geography, Taras Shevchenko National University of Lugansk, Lugansk, Ukraine, ORCID:

https://orcid.org/0000-0002-6246-325x, E-mail: nadya_gaev@mail.ru 